\title{
Restoration Potential of Bighorn Sheep in a Prairie Region
}

\section{Authors: Jesse D. Devoe, Blake Lowrey, Kelly M. Proffitt, and Robert A. Garrott}

This is the peer reviewed version of the following article: [Restoration Potential of Bighorn Sheep in a Prairie Region. The Journal of Wildlife Management 84, 7 p1256-1267, which has been published in final form at https://doi.org/10.1002/jwmg.21922. This article may be used for noncommercial purposes in accordance with Wiley Terms and Conditions for Use of Self-Archived Versions: https://authorservices.wiley.com/author-resources/Journal-Authors/licensing/selfarchiving.html\#3.

Devoe, Jesse D., Blake Lowrey, Kelly M. Proffitt, and Robert A. Garrott. "Restoration Potential of Bighorn Sheep in a Prairie Region." The Journal of Wildlife Management 84, no. 7 (July 9, 2020): 1256-1267. doi:10.1002/jwmg.21922. 
25 Jun 2020

Jesse DeVoe

Department of Ecology

Montana State University

Bozeman, MT 59718 (406)

599-3492

jessedevoe@gmail.com

RH: DeVoe et al. • Restoration of Prairie Bighorn Sheep

Restoration Potential of Bighorn Sheep in a Prairie Region

JESSE D. DEVOE, ${ }^{1}$ Fish and Wildlife Ecology and Management Program, Department of Ecology, Montana State University, Bozeman, MT 59718, USA

BLAKE LOWREY, Fish and Wildlife Ecology and Management Program, Department of Ecology, Montana State University, Bozeman, MT 59718, USA

KELLY M. PROFFITT, Montana Department of Fish, Wildlife and Parks, 1400 South $19^{\text {th }}$ Street, Bozeman, MT 59718, USA

ROBERT A. GARROTT, Fish and Wildlife Ecology and Management Program, Department of Ecology, Montana State University, Bozeman, MT 59718, USA

ABSTRACT Efforts to recover Rocky Mountain bighorn sheep (Ovis canadensis canadensis) throughout western North America have had limited success with the majority of current populations remaining in small and isolated areas on a fraction of their historical range. Prairie environments with rugged topography throughout the Northern Great Plains ecoregion were historically occupied by relatively robust bighorn sheep populations. We predicted there is likely unrealized potential habitat for restoring bighorn sheep to these areas; however, relatively little attention has been devoted to identifying habitat in unoccupied prairie regions. We used global positioning system (GPS)-collar data collected from 43 female bighorn sheep in 2 populations

\footnotetext{
${ }^{1}$ Email: jessedevoe@gmail.com
} 
located in the eastern Montana, USA, portion of the Northern Great Plains during 2014-2018 to estimate a population-level annual resource selection model and identify the important factors affecting bighorn sheep resource selection. We extrapolated model predictions across eastern Montana's prairie region and identified potential habitat to understand restoration potential and assist with future translocations of bighorn sheep. Resource selection of bighorn sheep was most strongly associated with terrain slope and ruggedness, tree canopy cover, and a normalized difference vegetation index metric. Within currently unoccupied areas of the historical range, the model extrapolation predicted $7,211 \mathrm{~km}^{2}$ of habitat, with most owned and managed by private landowners (44\%), Bureau of Land Management (33\%), and the United States Fish and Wildlife Service (15\%). Our results provide an empirical evaluation of landscape covariates influencing resource selection of bighorn sheep occupying prairie environments and provide a habitat model that may be generalizable to other areas in the Northern Great Plains ecoregion. We demonstrate substantial potential for restoration opportunities of bighorn sheep in the Northern Great Plains ecoregion. Broad restoration of bighorn sheep across the ecoregion would likely require strong collaboration among and between public resource managers, private landowners, and livestock producers given the heterogeneous land ownership patterns, management strategies, and domestic sheep distributions.

KEY WORDS bighorn sheep, historical range, Northern Great Plains ecoregion, Ovis canadensis, prairie, resource selection, restoration, translocation.

Rocky Mountain bighorn sheep (Ovis canadensis canadensis) remain in small and isolated populations on a fraction of their historical range (Buechner 1960, Geist 1971, Valdez and Krausman 1999, Krausman and Bleich 2013), in contrast to most large ungulate species in 
western North America, which have successfully recovered from population declines during the nineteenth century (e.g., Rocky Mountain elk [Cervus canadensis], mule deer [Odocoileus hemionus], and pronghorn [Antilocapra americana]; Picton and Lonner 2008). The currently estimated 50,000 bighorn sheep pales in comparison to the speculated 1.5-2 million that occupied their former range across the contiguous United States in the 1700s (Buechner 1960, Valdez and Krausman 1999, Singer et al. 2000c, Picton and Lonner 2008). Bighorn sheep were entirely extirpated in the Northern Great Plains ecoregion (Cowan 1940, Buechner 1960), an area comprising a substantial portion of historical bighorn sheep range extending throughout the prairie environments of Montana, Wyoming, North Dakota, South Dakota, and Nebraska, USA (Omernik and Griffith 2014). Even after nearly a century of restoration efforts to stem the primary factors associated with population declines (i.e., unregulated hunting, habitat loss, and competition with and transmission of disease-causing pathogens from domestic livestock), prairie environments currently host only a few $(<11)$ re-introduced populations of Rocky Mountain bighorn sheep (Toweill and Geist 1999, Montana Fish Wildlife and Parks 2010, Wiedmann and Hosek 2013, South Dakota Department of Game Fish and Parks 2018).

The limited success of bighorn sheep recovery in prairie regions is surprising given that the species is valued for cultural, viewing, and hunting purposes and receives considerable attention from public and private organizations to conserve and restore their populations (Singer et al. 2000c, Picton and Lonner 2008). Although broad restoration success may be inhibited by a variety of factors (e.g., low dispersal tendencies, lack of gene flow and diversity, disease, predation, and loss of migratory diversity; Shackleton et al. 1999, Singer et al. 2000b, Besser et al. 2013, Rominger 2018, Lowrey et al. 2019), lack of information regarding the availability and 
distribution of habitat may be an important constraint to restoration in some areas. Understanding patterns of resource selection and identifying habitat in currently unoccupied areas are valuable for promoting restoration of viable populations of bighorn sheep and providing benefits to the public as a valued wildlife resource (Berger 1990, Bleich et al. 1996, Epps et al. 2005, FestaBianchet et al. 2006, Brewer et al. 2014). Given the widespread historical distribution of bighorn sheep across the prairie regions that remain unoccupied (Couey 1950, Buechner 1960), there are likely extensive areas with unrealized potential for restoring bighorn sheep populations to these areas.

There is a need to provide managers with biologically based information about the distribution of bighorn sheep habitat, which can be used in combination with prevailing policies and local knowledge of public hunter access and domestic sheep distributions to improve translocation decisions. Habitat models constructed from locations collected from global positioning system (GPS)-collars can identify influential habitat attributes and can be predicted spatially to represent potential habitat across large landscapes (Boyce and McDonald 1999, Johnson et al. 2006). Predictions of potential habitat can assist managers in identifying unoccupied habitat or possible translocation sites (Cianfrani et al. 2010, Hovick et al. 2015) and are an effective tool to increase the probability of translocation success (Griffith et al. 1989, Zeigenfuss et al. 2000). Previous researchers contributed important information on habitat attributes and identified areas suitable for restoration of bighorn sheep in prairie regions based on information collected from observational surveys (Fairbanks et al. 1987, Wockner et al. 2003,

Singer and Schoenecker 2004), very high frequency radio-collar locations (Moses et al. 1996, Lewis 1998, Hickey 2000, Zimmerman 2008), and prior habitat evaluations (Sweanor et al. 
1996, Singer and Gudorf 1999, Forbes 2001, Zimmerman et al. 2006). The use of data collected from GPS-collars to develop habitat models to assist with translocations, however, has not been broadly incorporated into restoration of bighorn sheep in the prairie regions. Such tools provide opportunities to further advance our understanding of habitat associations and restoration potential throughout prairie environments and complement foundational knowledge developed prior to the advent of GPS-collars (Hebblewhite and Haydon 2010, Tomkiewicz et al. 2010, Lula et al. 2020).

Given the limited current distributions of bighorn sheep compared to historical distributions in the prairie regions, we propose that the historical range is capable of supporting additional populations of bighorn sheep. In the eastern prairie region of Montana, for example, restored populations currently occupy an estimated $5.9 \%$ of the historical range (Couey 1950, Montana Fish Wildlife and Parks 2010). We further propose that areas outside historical ranges may provide additional restoration potential, given likely uncertainties in estimates of historical distributions. The objectives of our observational study were to identify resource selection patterns of bighorn sheep in prairie landscapes using GPS technology and develop spatial predictions of bighorn sheep habitat within and outside of the historical range in eastern Montana in an effort to characterize the potential for restoration in the prairie regions and help with future translocation programs.

\section{STUDY AREA}

We conducted our study from 2014 - 2018 in 2 areas adjoining the Missouri River in the Northern Great Plains ecoregion in eastern Montana: Fergus $\left(786.5 \mathrm{~km}^{2} ; 689-1,066 \mathrm{~m}\right.$ above sea level) and Middle Missouri Breaks (141.2 km²; 678-972 m above sea level; Fig. 1). These areas 
typify the mixed grass prairie and badland (i.e., breaks) environments present across the prairie region of eastern Montana. Fergus was located primarily within the Upper Missouri Breaks National Monument approximately $80 \mathrm{~km}$ south of Havre, Montana. Middle Missouri Breaks was located approximately $95 \mathrm{~km}$ east of Fergus, on the north side of Fort Peck Lake of the Missouri River, and primarily within the Charles M. Russell National Wildlife Refuge. Both areas were characterized as breaks topography with extensively eroded sedimentary rock layers producing numerous gullies and ravines with steep, sparsely vegetated slopes. More even terrain and flatter benches with predominantly dry, savanna-steppe woodland and mixed grass prairie were at upper reaches of drainages. Sagebrush steppe was distributed throughout mid to low elevations. Cultivated cropland that consisted mostly of common wheat and leguminous forbs (e.g., field peas, lentils, alfalfa) occurred on higher elevation benches and primarily in Fergus.

Climate was similar in both study areas and characterized by short, warm summers $(21.6$ ${ }^{\circ} \mathrm{C}$ mean Jul temperature) and long, cold winters $\left(-6.4{ }^{\circ} \mathrm{C}\right.$ mean Jan temperature) with mean annual precipitation ranging $276.9 \mathrm{~mm}$ to $378.6 \mathrm{~mm}$ (PRISM Climate Group 2016). During our study, annual precipitation and temperature averaged $329.9 \mathrm{~mm}$ and $6.5^{\circ} \mathrm{C}$, respectively. Ownership within Fergus included Bureau of Land Management (BLM; 64\%), state of Montana (7\%), and private properties primarily used as ranchlands (29\%) with a mixture of grazing and agricultural production. Ownership within Middle Missouri Breaks included United States Fish and Wildlife Service (USFWS; 53\%), BLM (29\%), state of Montana (6\%), and private lands primarily used as ranchlands (12\%). Mule deer, white-tailed deer (O. virginianus), and elk were sympatric with bighorn sheep in the study areas. Potential predators of bighorn sheep that 
occupied the study areas included mountain lion (Puma concolor), bobcat (Lynx rufus), coyote (Canis latrans), and golden eagle (Aquila chrysaetos).

Each study area had well-established populations of bighorn sheep that originated from translocated individuals originally captured and translocated from mountain environments of western Montana (McCarthy 1996, Hickey 2000, Montana Fish Wildlife and Parks 2010). The Fergus population originated from a series of introductions from 1958-1980, and the Middle Missouri Breaks population originated from individuals dispersing from an introduction in 1980 located $21 \mathrm{~km}$ to the west. In 2017, minimum counts of bighorn sheep were 226 and 211 individuals in the Fergus and Middle Missouri Breaks populations, respectively. During the fall hunting seasons (Sep-Nov) of 2015-2017, an average of 45 and 44 bighorn sheep (including males and females) were harvested each year in the Fergus and Middle Missouri Breaks populations, respectively.

\section{METHODS}

We captured 25 adult (>1.5 yrs old) female bighorn sheep in Fergus in December 2014 and 2016 and 18 adult female bighorn sheep in Middle Missouri Breaks in December 2016 (those captured in Middle Missouri Breaks excludes 1 individual that died soon after capture and 1 individual with a collar that failed to release). We captured individuals using helicopter net gunning in accordance with animal welfare protocols approved by the Montana State University Institutional Animal Care and Use Committee (permit 2014-32). We instrumented individuals with store-onboard GPS radio-collars (Telonics TGW-4400-3; Telonics, Mesa, AZ, USA) programmed to record a spatial location every 4 hours and release from the animal after 1-2 years. After retrieving the collars and downloading the location data, we removed locations with low spatial 
precision (horizontal dilution of precision values $>10$ and horizontal error estimates $>60 \mathrm{~m}$; D’Eon and Delparte 2005, Lowrey et al. 2017). After censoring, mean fix success rate of individual bighorn sheep was $97.1 \pm 0.01 \%$ (SD).

We developed a resource selection function (RSF) model to estimate the relative probability of bighorn sheep selection as a function of landscape attributes within Fergus and Middle Missouri Breaks (Manly et al. 2002) and extrapolated the model to prairie environments of eastern Montana. To develop the RSF model, we compared the habitat attributes of observed GPS (i.e., used) locations, treating individual animals as the sample unit, with available locations randomly generated within the annual range of each population using generalized linear mixedeffect models, the inverse link function, and scaled and centered covariates (Manly et al. 2002, Gillies et al. 2006). We defined the annual range of each population using a $95 \%$ kernel density contour based on used locations combined across all individuals within each population. We selected available locations at a 1:10 (used:available) ratio to adequately describe the distribution of each habitat covariate and to avoid model convergence issues (Northrup et al. 2013). We performed data processing and analyses using the sf (Pebesma 2018), raster (Hijmans 2020), tidyverse (Wickham et al. 2019), and lme4 (Bates et al. 2015) packages in the R environment for statistical computing (R Core Team 2020).

We pooled datasets across seasons (e.g., summer [Jul-Sep] and winter [Dec-Mar]) and study areas to develop a single model of annual range habitat. We determined that pooling was reasonable by assessing the percent overlap of individual bighorn sheep seasonal ranges in each study area, comparing density distributions of covariates for used and available locations for each season and study area, and performing a cross-validation procedure (Boyce et al. 2002) to 
evaluate the predictive ability of RSF models across seasons and study areas (Section SA, available online in Supporting Information).

\section{Resource Covariates}

We developed covariates representing landscape attributes that we hypothesized to influence resource selection of bighorn sheep based on the literature and evaluated these hypotheses through a model selection process (Table 1). Our covariates fell within 2 suites: terrain and vegetation. The terrain suite included slope (Fairbanks et al. 1987, Moses et al. 1996, Hickey 2000, DeCesare and Pletscher 2006) and 2 measures of ruggedness: slope variance, calculated as the squared standard deviation of slope (DeVoe et al. 2015; Lowrey et al. 2017, 2018), and vector ruggedness measure (VRM), which integrated variation in slope and aspect (Sappington et al. 2007, Poole et al. 2016).

The vegetation suite included tree canopy cover from the 2011 National Land Cover Database (https://www.mrlc.gov/data/nlcd-2011-usfs-tree-canopy-cover-conus, accessed $1 \mathrm{Jul}$ 2019) and 2 competing measures of normalized difference vegetation index (NDVI) values: NDVI amplitude and NDVI time-integrated. We used canopy cover to represent areas that bighorn sheep may avoid to enhance visibility of potential predators (Smith et al. 1991, Johnson and Swift 2000). We derived NDVI amplitude and NDVI time-integrated from the moderate resolution imaging spectroradiometer (MODIS) product MOD09Q1 (https://lpdaac.usgs.gov/data_access/data_pool, accessed 1 Jul 2019) by averaging smoothed and interpolated NDVI values that we annually summarized across the growing season from May to October 2014 to 2017 (Ruimy et al. 1994, Chen et al. 2004, Jönsson and Eklundh 2004, Bradley et al. 2007). We used NDVI amplitude and NDVI time-integrated as single measures of primary 
productivity for the duration of the study to represent areas with more abundant forage (Pettorelli et al. 2011, Lowrey et al. 2018, Lula et al. 2020). We predicted that the NDVI covariates would be positively associated with bighorn sheep selection.

\section{Statistical Framework and Model Selection We}

used the exponential RSF:

$$
w w(x x)=\exp \beta \beta 0 w w+(i i x x \beta \beta)_{1} 1 x x_{1}+\beta \beta \beta \beta 20 x x 2+\cdots+\beta \beta n n x x_{n n} \quad \beta \beta^{\prime} s s
$$

to calculate relative probability of use , where is the intercept, and are the coefficients of the effects of covariates, $x x$. We used individual bighorn sheep as the sample unit (White and Garrott 1990) and specified a random intercept for each individual to account for unbalanced samples sizes among individuals and non-independence of GPS locations within individuals (Gillies et al. 2006, Fieberg et al. 2010).

To select a final RSF model for extrapolation, we conducted model selection in a tiered approach following similar approaches to DeVoe et al. (2015) and Lowrey et al. (2017). We used this approach to progress from univariate to multivariate models for identifying the most explanatory combination of covariates (Table 1) and their associated functional form (Franklin et al. 2000). In each tier, we ranked and selected models based on corrected Akaike's Information Criterion $\left(\mathrm{AIC}_{c}\right.$; Burnham and Anderson 2002). In tier 1, we evaluated univariate models to compete different functional forms for some covariates (Table 1) and selected the top-ranked 
functional form for each covariate. In tier 2, we competed covariates measuring similar landscape attributes (e.g., NDVI amplitude and NDVI time-integrated) and selected the topranked metric. In tier 3, we fit multivariate models containing the covariates and functional forms selected in tiers 1 and 2 . In this tier, we first developed a base terrain model from an evaluation of all non-collinear combinations of terrain covariates (i.e., slope, slope variance, and VRM), and then built upon the base terrain model with an evaluation of all combinations of remaining covariates (Lowrey et al. 2017). In all multivariate models, we excluded pairs of covariates with a Pearson's correlation coefficient of $|r|>0.6$ (Fig. S4, available online in Supporting Information).

We used a $k$-fold cross-validation to assess predictive performance of our final RSF model (Boyce et al. 2002). For each of 5 folds, we built a model using $80 \%$ of the data to estimate predicted RSF values and withheld $20 \%$ for model validation. We then summed the occurrence of used locations within 10 equal-area RSF bins and evaluated correlation between frequency of occurrence and relative RSF score using the Spearman rank correlation coefficient $\left(r_{\mathrm{s}}\right)$.

\section{Model Extrapolation}

We used our final RSF model to develop spatial predictions of RSF values across the prairie region of eastern Montana. We considered the prairie region as the area generally bounded by the Montana state border and the furthest western distribution of both mixed grass prairie and breaks cover types that typify prairie landscapes occupied by bighorn sheep in Montana. Within the broad extrapolation area, we constrained the prediction by excluding areas that represent mountainous environments (generally elevations $>1,400 \mathrm{~m}$ ), excluding large bodies of water 
(e.g., Fort Peck Lake, Missouri River), and only extrapolating over the range of covariate values present in the data that we used in model development.

Within the prairie region, we obtained an estimate of the historical (i.e., prior to European colonization) range of bighorn sheep (Couey 1950) to summarize potential habitat. The estimated historical range included distributions identified for Rocky Mountain and Audubon ecotypes (Couey 1950, Wehausen and Ramey 2000) of bighorn sheep, but we constrained it to lower elevation areas (generally $<1,400 \mathrm{~m}$; e.g., excluding montane areas). Within the estimated historical range, we extrapolated our top model in currently unoccupied areas by excluding our study areas and general distribution areas for several other bighorn sheep populations identified by Montana Fish, Wildlife and Parks (http://gis-mtfwp.opendata.arcgis.com, accessed 15 Jul 2019). We retained the intercept term, $\beta \beta_{0}$, when generating predictions within the mixed-model framework (Gillies et al. 2006, Hebblewhite and Merrill 2008, Laforge et al. 2015). We then applied a linear stretch to rescale predicted RSF values between 0 and 1 (Johnson et al. 2004):

$$
w w=w w w w(x x)---w w w w m m i i n n
$$

mmmmmm mmiinn

\begin{abstract}
Although we did not have an external data source to evaluate generalizability of our model beyond the study areas, the strong similarity in resource selection patterns between our study areas was an indication that the broad extrapolation across the prairie region was appropriate (Fig. S3, available online in Supporting Information).
\end{abstract}


To estimate potential habitat across the prairie region, we first defined habitat as pixels with a predicted RSF value greater than or equal to the lower $5 \%$ of the RSF values from used locations (DeVoe et al. 2015, Lowrey et al. 2017). We then quantified amount of habitat for the estimated historical range and currently unoccupied areas of the estimated historical range. In addition, we summarized habitat in currently unoccupied areas of the estimated historical range across general land ownership (e.g., private, state of Montana, BLM; http://svc.mt.gov/msl/mtcadastral, accessed 15 Jul 2019).

\section{RESULTS}

We monitored 43 adult female bighorn sheep in Fergus and Middle Missouri Breaks for an average of 485 days (range $=196-583)$. We obtained 121,489 GPS locations $(75,698$ and 45,791 in Fergus and Middle Missouri Breaks, respectively), or an average of 2,825 (range = 1,1503,462 ) locations/individual. We recorded 16 mortalities (harvest $=63 \%$, unknown $=31 \%$, capture $=6 \%$ ) during the study. Average covariate values varied across used and available datasets for terrain and vegetation covariates (Table S1, available online in Supporting Information).

In tier 1, there was a clear top-ranked functional form for each covariate (Table 2). With the exception of slope, which was best characterized as quadratic, the pseudothreshold form was top-ranked for all covariates considered (slope variance, VRM, and canopy cover) in this tier. In tier 2, NDVI amplitude clearly out-ranked NDVI time-integrated (Table 2). In tier 3, we competed 5 models evaluating all combinations of top-ranked terrain covariates from tier 1 to determine a top-ranked base terrain model. The resulting base terrain model included the multivariate combination of squared slope and pseudothreshold VRM, which out-ranked the 
next-best model, squared slope and pseudothreshold slope variance, by $8,026 \mathrm{AIC}_{c}$. When evaluated with the other top-ranked covariates from tiers 1 and 2, our top-ranked RSF model contained squared slope, pseudothreshold VRM, pseudothreshold canopy cover, and linear NDVI amplitude (Table 2; Fig. 2).

As expected, bighorn sheep generally selected for areas with steeper and more rugged terrain based on coefficient estimates from the top-ranked model (Figs. 2 and S5; Table S2, available online in Supporting Information). Vector ruggedness measure was the most influential covariate and indicated selection for more rugged areas that began to asymptote as VRM increased. The quadratic form of slope indicated selection was highest at moderate levels of slope $\left(\sim 38.8^{\circ}\right)$. For the vegetation covariates, the pseudothreshold form of canopy cover indicated a negative relationship, with selection leveling to a relatively flat prediction line beyond approximately 3-5\% canopy cover. Contrary to our prediction, however, we found a negative relationship with NDVI amplitude. The $k$-fold cross validation procedure to assess the predictive performance of our final RSF model showed strong correlation between frequency of occurrence and relative RSF score (average $r_{s}=1.0$ [range $\left.=1.0-1.0\right]$ ), indicating excellent predictive performance.

The estimated historical range spanned $40,599 \mathrm{~km}^{2}$ and was primarily comprised of private (61\%), BLM (19\%), USFWS (7\%), State of Montana (6\%), and United States Department of Agriculture (1\%) ownerships. Covariate values in the estimated historical range were largely within the range of and distributed similarly to those in the model development area (Fig. S6, available online in Supporting Information). Currently unoccupied areas within the estimated historical range spanned $38,046 \mathrm{~km}^{2}$ (93.7\%). Based on an RSF cutpoint of 0.0011 
used to define habitat in our RSF prediction, we identified $8,396 \mathrm{~km}^{2}$ of habitat in the estimated historical range (20.7\%; Fig. 3), of which 7,211 km² occurred in areas currently unoccupied by bighorn sheep (19.0\%). The distribution of habitat was patchy across the estimated historical range and highlighted areas with the most rugged terrain. In areas of the estimated historical range currently unoccupied by bighorn sheep, habitat was primarily comprised of private (44.1\%), BLM (33.0\%), and USFWS ownership (15.1\%; Table 3).

\section{DISCUSSION}

Our study provides an empirical evaluation based on GPS-collar data of landscape covariates influencing bighorn sheep selection in a prairie region. Bighorn sheep are characteristically associated with rugged and steep terrain in montane and prairie environments (Fairbanks et al. 1987, Hickey 2000, Johnson and Swift 2000, DeCesare and Pletscher 2006, Lula et al. 2020), and we found terrain ruggedness and slope to be the most influential landscape attributes predicting habitat use in the prairie. Bighorn sheep selected for areas of greater ruggedness (Sappington et al. 2007) and with intermediate slopes (optimal $\left.39^{\circ}\right)$. Previous work has indicated that bighorn sheep habitat selection in the prairie is strongly related to slope either with a positive linear association (Hickey 2000, Wockner et al. 2003, Singer and Schoenecker 2004, Zimmerman 2008) or maximized at intermediate levels (optimal 31-39; Fairbanks et al. 1987). Our study directly compared linear and quadratic functional forms of slope and provides support for intermediate slope values, which aligns with other studies of bighorn sheep occupying montane environments (Lula et al. 2020) and other mountain ungulates (DeVoe et al. 2015; Lowrey et al. 2017, 2018). Bighorn sheep in our study also selected for areas with lower tree canopy cover and NDVI amplitude. Selection for reduced canopy cover may be related to 
enhanced visibility for detecting predators in areas of less forest structure (Geist 1971, Smith et al. 1991, Johnson and Swift 2000); however, our results indicated that, relative to selection for other landscape attributes, selection for canopy cover only marginally decreased over the range of values observed in our study areas, indicating a relatively weak association with bighorn sheep selection. This pattern of selection may be due to foraging opportunities provided by forested areas (Fairbanks et al. 1987). The selection of bighorn sheep for lower values of NDVI amplitude was counter to our hypothesized relationship. Our results may be influenced by the dominant selection for rugged and steep terrain, which are typically associated with low NDVI values - a pattern that has been observed in studies of other mountain ungulates (Lowrey et al. 2017). It may be that bighorn sheep are selecting for NDVI but at finer scales than we used in our study. In addition, the relationship between bighorn sheep forage and NDVI has not been evaluated; therefore, the utility of NDVI as a surrogate for forage availability is uncertain.

Restoration of bighorn sheep in Montana and other western states has focused predominantly on mountainous landscapes; however, the majority of these restored populations remain at low abundances and marginal long-term viability decades after being established (Buechner 1960, Toweill and Geist 1999, Montana Fish Wildlife and Parks 2010). In contrast, our 2 restored prairie populations have proven to be demographically robust and provide substantial consumptive and non-consumptive opportunities to the public and local residents. For example, both study populations supported a female harvest, which was the dominant source of mortality of our study animals. Additionally, the study populations have provided source individuals for 7 transplant operations since 2000 of nearly 150 individuals translocated to other areas in Montana and other western states (Montana Fish Wildlife and Parks 2010). Our study 
suggests that extensive potential habitat may exist in prairie environments beyond the current distribution of bighorn sheep and that, if occupied, could potentially increase the abundance and distribution of bighorn sheep and provide additional consumptive and non-consumptive recreational opportunities.

Our predictions of bighorn sheep habitat in eastern Montana demonstrate the utility of the model for identifying potential restoration sites with high quality bighorn habitat for starting new populations or expanding present population ranges that may have application to other regions in the Northern Great Plains. Bighorn sheep translocations are a useful management tool for increasing abundance and distribution, improving metapopulation structure (Singer et al. 2000a), promoting natural recolonization of unoccupied habitat (Bleich et al. 1996), encouraging genetic diversity (Epps et al. 2010), and lowering risk of disease events by reducing densities in the source population (Sells et al. 2015). Studies have highlighted the importance of focusing on restoring metapopulation structure to maximize the likelihood of successful translocations and achieving higher abundances and broader distributions of bighorn sheep (Bleich et al. 1996, 2018; Singer et al. 2000a; Lula et al. 2020), which may maximize resilience to disease (Singer et al. 2001, Manlove et al. 2014, Cassirer et al. 2018). Although management agencies recognize the importance of metapopulation structure and connectivity to long-term viability and persistence of populations (Brewer et al. 2014), current policies may preclude translocations to areas that enhance connectivity because of concerns of the transmission of novel pathogens between populations or from domestic sheep (George et al. 2009). Alternatively, the use of shortrange translocations from existing populations may promote exploration and colonization of 
unoccupied habitat, decrease the number of generations needed to naturally colonize unoccupied habitat, and reduce risk of introducing novel pathogens to existing populations (Butler et al. 2017, Bleich et al. 2018, Jesmer et al. 2018, Lula et al. 2020).

Restoration of bighorn sheep, however, may be limited by disease exposure and current policies regarding translocations and population re-establishment that vary by state and federal natural resource agencies in the United States. Because of the potential of domestic sheep to transmit pathogens that cause respiratory disease and increased mortality risk in bighorn sheep (Besser et al. 2013, 2014), policies restrict translocations to areas that provide for some level of separation between domestic and bighorn sheep, which may include large spatial distances (generally $\geq 23 \mathrm{~km}$ ), non-overlap in the temporal use of similar areas, or other physical barriers (e.g., waterbodies; Montana Fish Wildlife and Parks 2010, Wild Sheep Working Group 2012, U.S. Forest Service 2015). Some states permit restoration to areas that expand existing ranges or bolster genetic diversity but not to areas that improve connectivity between populations to mitigate the risk of pathogen transmission (Singer and Gudorf 1999, George et al. 2009). Domestic sheep in eastern Montana currently number approximately 167,000 animals (National Agricultural Statistics Service 2020); however, we were not able to assess the juxtaposition of predicted habitat relative to areas occupied by domestic sheep because scant information is available on domestic sheep distributions, particularly on private lands. As a result, although our study provides a useful biological model to help with restoration of bighorn sheep in eastern Montana, our estimates of predicted habitat are likely overestimates of the practical reality of restoration potential. Full restoration potential of bighorn sheep with respect to domestic sheep is a dynamic target because the abundance and distribution of domestic sheep is often changing 
with markets, range conditions, and land ownerships. For example, from the 5.7 million domestic sheep in 1903, Montana now has near-record lows of approximately 219,000 (National Agricultural Statistics Service 2020). To reduce the risk of commingling between these species and further define potential restoration sites, restoration planning and implementation will need to occur at the local level with state, federal, and private partners who have detailed knowledge of domestic sheep distributions. To realize the full biological potential of bighorn sheep restoration in the prairie region, innovative partnerships between natural resource agencies and private landowners are needed to resolve obstacles related to commingling of bighorn sheep with domestic livestock. This may include incorporating into translocation decisions a local assessment of the level of risk that the public and natural resource agencies are willing to accept in regards to pathogen transmission. In addition, further research is needed to understand the disease processes and transmission for refining policies and decision-making.

Further, several states' management plans for restoring bighorn sheep prioritize establishment of new populations to areas of identified habitat that are primarily public lands accessible by the hunting public and that were historically occupied by bighorn sheep (Montana Fish Wildlife and Parks 2010, Wiedmann and Hosek 2013, South Dakota Department of Game Fish and Parks 2018). Given that private lands comprise approximately $76 \%$ of the Northern Great Plains ecoregion (Freese et al. 2010) and are where domestic sheep primarily occur, these policies may substantially constrain restoration opportunities. In our study, predicted habitat within the unoccupied portions of the estimated historical range was primarily distributed across 4 land ownership types that included private (44.1\%), BLM (33.0\%), USFWS (15.1\%), and state of Montana (6.8\%; Table 3). Although opportunities for restoration exist in areas that are 
predominantly publicly owned within the historical range, the broad and mosaicked distribution

of private lands (Fig. 4) that contain predicted habitat limits restoration potential of bighorn sheep under current policies. In Montana and other states with similar policies, broad restoration of bighorn sheep would require strong collaboration between private and public jurisdictions to lessen restrictions of public hunter access on private lands. Otherwise, policy changes would be needed to allow establishment of populations on private lands that may not be adjacent to public land or permit public hunter access. In Montana and states with similar policies, policy changes that permit restoration in areas outside the estimated bighorn sheep historical range could further enhance restoration successes.

\section{MANAGEMENT IMPLICATIONS}

Resource managers interested in restoration of bighorn sheep should consider prairie regions as additional opportunities for establishing and enhancing populations. Our habitat model may be useful for identifying potential translocation sites in mixed grass prairie and breaks regions and other similar prairie environments in the Northern Great Plains. Where relatively contiguous yet unoccupied habitat exists, managers could consider using short-range translocations aimed at enlarging the ranges of current populations and restoring metapopulation structure. Where habitat exists on a mosaic of public and private lands, strong collaborations among and between public resource agencies and private landowners will be necessary to restore bighorn sheep. Where potential translocation sites occur near domestic sheep, resource agencies could consider developing collaborations with domestic sheep producers to relocate domestic sheep, convert grazing allotments on public lands from domestic sheep to cattle, or identify innovative and proactive management techniques that could reduce the probability of pathogen transmission. An 
assessment of the level of risk that the public and resource managers are willing to accept concerning pathogen transmission could additionally be incorporated into translocation decisions. Depending on current states' policies, altering restoration policy to permit establishment of bighorn populations in areas of suitable yet unoccupied habitat that may be predominantly privately owned or not adjacent to large tracts of publicly owned lands and that may be outside the estimated historical range of bighorn sheep could substantially enhance restoration success. Organizations interested in using our model for restoration planning should consider that additional landscape attributes (e.g., water availability, land use, development; Smith et al. 1991, Zimmerman 2008) could not be accurately incorporated into our model and may need to be evaluated locally and that other unmeasured landscape attributes that influence bighorn sheep selection may exist.

\section{ACKNOWLEDGMENTS}

We thank pilots D. Hitch, M. S. Stott, and R. C. Swisher for successful capture of study animals, and we thank S. S. Anderson, C. J. Butler, B. E. Dorak, E. S. Lula, S. A. Hemmer, F. D. Henry, and G. Taylor for logistical and field support. We additionally thank J. T. Paterson for insightful discussion and development of covariates, and we thank J. A. Gude, K. A. Schoenecker, and 2 anonymous reviewers for constructive comments on earlier drafts of the manuscript. Funding for this work was provided by Fish, Wildlife and Parks and the annual auction sale of a Montana bighorn sheep hunting license.

\section{LITERATURE CITED}

Bates, D., M. Maechler, B. Bolker, and S. Walker. 2015. Fitting linear mixed-effects models using lme4. Journal of Statistical Software 67:1-48.

DeVoe et al. 21 
Berger, J. 1990. Persistence of different-sized populations: an empirical assessment of rapid extinctions in bighorn sheep. Conservation Biology 4:91-98.

Besser, T. E., E. F. Cassirer, M. A. Highland, P. Wolff, A. Justice-Allen, K. Mansfield, M. Davis, and W. Foreyt. 2013. Bighorn sheep pneumonia: sorting out the cause of a polymicrobial disease. Preventive Veterinary Medicine 108:85-93.

Besser, T. E., E. F. Cassirer, K. A. Potter, K. Lahmers, J. L. Oaks, S. Shanthalingam, S. Srikumaran, and W. J. Foreyt. 2014. Epizootic pneumonia of bighorn sheep following experimental exposure to Mycoplasma ovipneumoniae. PLoS ONE 9:e110039.

Bleich, V. C., G. A. Sargeant, and B. P. Wiedmann. 2018. Ecotypic variation in population dynamics of reintroduced bighorn sheep. Journal of Wildlife Management 82:8-18.

Bleich, V. C., J. D. Wehausen, R. R. Ramey, and J. L. Rechel. 1996. Metapopulation theory and mountain sheep: implications for conservation. Pages 353-373 in D. R. McCullough, editor. Metapopulations and wildlife conservation. Island Press, Washington, D.C., USA.

Boyce, M. S., and L. L. McDonald. 1999. Relating populations to habitats using resource selection functions. Trends in Ecology \& Evolution 14:268-272.

Boyce, M. S., P. R. Vernier, S. E. Nielsen, and F. K. A. Schmiegelow. 2002. Evaluating resource selection functions. Ecological Modelling 157:281-300.

Bradley, B. A., R. W. Jacob, J. F. Hermance, and J. F. Mustard. 2007. A curve fitting procedure to derive inter-annual phenologies from time series of noisy satellite NDVI data. Remote Sensing of Environment 106:137-145.

Brewer, C., V. C. Bleich, J. Foster, T. Hosch-Hebdon, D. E. McWhirter, and E. M. Rominger. 2014. Bighorn sheep conservation challenges: Management strategies for the 21 st century. 
2014. Western Association of Fish and Wildlife Agencies, Cheyenne, Wyoming, USA.

Buechner, H. K. 1960. The bighorn sheep in the United States, its past, present, and future. Wildlife Monographs 4:3-174.

Burnham, K. P., and D. R. Anderson. 2002. Model selection and multimodel inference: a practical information-theoretic approach. Second edition. Springer-Verlag, Berlin, Germany.

Butler, C. J., W. H. Edwards, J. E. Jennings-Gaines, H. J. Killion, M. E. Wood, D. E. McWhirter, J. T. Paterson, K. M. Proffitt, E. S. Almberg, P. J. White, et al. 2017. Assessing respiratory pathogen communities in bighorn sheep populations: sampling realities, challenges, and improvements. PLoS ONE 12:e0180689.

Cassirer, E. F., K. R. Manlove, E. S. Almberg, P. L. Kamath, M. Cox, P. Wolff, A. Roug, J. Shannon, R. Robinson, R. B. Harris, et al. 2018. Pneumonia in bighorn sheep: risk and resilience. Journal of Wildlife Management 82:32-45.

Chen, J., P. Jönsson, M. Tamura, Z. Gu, B. Matsushita, and L. Eklundh. 2004. A simple method for reconstructing a high-quality NDVI time-series data set based on the Savitzky-Golay filter. Remote Sensing of Environment 91:332-344.

Cianfrani, C., G. Le Lay, A. H. Hirzel, and A. Loy. 2010. Do habitat suitability models reliably predict the recovery areas of threatened species? Journal of Applied Ecology 47:421-430.

Couey, F. M. 1950. Rocky Mountain bighorn sheep of Montana. Bulletin No. 2, Montana Fish and Game Commission, Helena, USA.

Cowan, I. M. 1940. Distribution and variation in the native sheep of North America. American Midland Naturalist 24:505. 
D’Eon, R. G., and D. Delparte. 2005. Effects of radio-collar position and orientation on GPS radio-collar performance, and the implications of PDOP in data screening. Journal of Applied Ecology 42:383-388.

DeCesare, N. J., and D. H. Pletscher. 2006. Movements, connectivity, and resource selection of Rocky Mountain bighorn sheep. Journal of Mammalogy 87:531-538.

DeVoe, J. D., R. A. Garrott, J. J. Rotella, S. R. Challender, P. J. White, M. O’Reilly, and C. J. Butler. 2015. Summer range occupancy modeling of non-native mountain goats in the greater Yellowstone area. Ecosphere 6:217.

Epps, C. W., P. J. Palsbøll, J. D. Wehausen, G. K. Roderick, R. R. Ramey, and D. R. McCullough. 2005. Highways block gene flow and cause a rapid decline in genetic diversity of desert bighorn sheep. Ecology Letters 8:1029-1038.

Epps, C. W., J. D. Wehausen, P. J. Palsbøll, and D. R. McCullough. 2010. Using genetic tools to track desert bighorn sheep colonizations. Journal of Wildlife Management 74:522-531.

Fairbanks, W. S., J. A. Bailey, and R. S. Cook. 1987. Habitat use by a low-elevation, semicaptive bighorn sheep population. Journal of Wildlife Management 51:912.

Festa-Bianchet, M., T. Coulson, J.-M. Gaillard, J. T. Hogg, and F. Pelletier. 2006. Stochastic predation events and population persistence in bighorn sheep. Proceedings of the Royal Society B 273:1537-1543.

Fieberg, J., J. Matthiopoulos, M. Hebblewhite, M. S. Boyce, and J. L. Frair. 2010. Correlation and studies of habitat selection: problem, red herring or opportunity? Philosophical Transactions of the Royal Society of London. Series B, Biological Sciences 365:22332244. 
Forbes, K. M. 2001. Modeling bighorn sheep habitat in northwest Nebraska. Thesis, University of Nebraska-Lincoln, Lincoln, USA.

Franklin, A. B., D. R. Anderson, R. J. Gutiérrez, and K. P. Burnham. 2000. Climate, habitat quality, and fitness in northern spotted owl populations in northwestern California. Ecological Monographs 70:539-590.

Freese, C., D. Montanye, and S. Forrest. 2010. Proposed standards and guidelines for private nature reserves in the Northern Great Plains. Great Plains Research 20:71-84.

Geist, V. 1971. Mountain sheep: a study in behavior and evolution. University of Chicago Press, Chicago, Illinois, USA.

George, J. L., R. Kahn, W. M. Miller, and B. Watkins. 2009. Colorado bighorn sheep management plan: 2009-2019. Special report number 81. Colorado Division of Wildlife, Denver, USA.

Gillies, C. S., M. Hebblewhite, S. E. Nielsen, M. A. Krawchuk, C. L. Aldridge, J. L. Frair, D. J. Saher, C. E. Stevens, C. L. Jerde, M. A. Krawchukt, and D. J. Sahert. 2006. Application of random effects to the study of resource selection by animals. Journal of Animal Ecology 75:887-898.

Griffith, B., J. M. Scott, J. W. Carpenter, and C. Reed. 1989. Translocation as a species conservation tool: status and strategy. Science 245:477-480.

Hebblewhite, M., and D. T. Haydon. 2010. Distinguishing technology from biology: a critical review of the use of GPS telemetry data in ecology. Philosophical Transactions of the Royal Society B: Biological Sciences 365:2303-2312.

DeVoe et al. 25 
Hebblewhite, M., and E. H. Merrill. 2008. Modelling wildlife-human relationships for social species with mixed-effects resource selection models. Journal of Applied Ecology 45:834844.

Hickey, W. C. 2000. A GIS-based approach to landscape habitat selection by bighorn sheep in the Missouri River Breaks, Montana. Thesis, Montana State University, Bozeman, USA.

Hijmans, R. J. 2020. Raster: geographic data analysis and modeling. R package version 3.0-12. Hovick, T. J., D. K. Dahlgren, M. Papeş, R. D. Elmore, and J. C. Pitman. 2015. Predicting greater prairie-chicken lek site suitability to inform conservation actions. PLoS ONE 10:e137021.

Jesmer, B. R., J. A. Merkle, J. R. Goheen, E. O. Aikens, J. L. Beck, A. B. Courtemanch, M. A. Hurley, D. E. McWhirter, H. M. Miyasaki, K. L. Monteith, and M. J. Kauffman. 2018. Is ungulate migration culturally transmitted? Evidence of social learning from translocated animals. Science 361:1023-1025.

Johnson, C. J., S. E. Nielsen, E. H. Merrill, T. L. McDonald, and M. S. Boyce. 2006. Resource selection functions based on use-availability data: theoretical motivation and evaluation methods. Journal of Wildlife Management 70:347-357.

Johnson, C. J., D. R. Seip, and M. S. Boyce. 2004. A quantitative approach to conservation planning: using resource selection functions to map the distribution of mountain caribou at multiple spatial scales. Journal of Applied Ecology 41:238-251.

Johnson, T. L., and D. M. Swift. 2000. A test of a habitat evaluation procedure for Rocky Mountain bighorn sheep. Restoration Ecology 8:47-56.

Jönsson, P., and L. Eklundh. 2004. TIMESAT — a program for analyzing time-series of satellite sensor data. Computers \& Geosciences 30:833-845. 
Krausman, P. R., and V. C. Bleich. 2013. Conservation and management of ungulates in North America. International Journal of Environmental Studies 70:372-382.

Laforge, M. P., E. Vander Wal, R. K. Brook, E. M. Bayne, and P. D. McLoughlin. 2015.

Process-focussed, multi-grain resource selection functions. Ecological Modelling 305:1021.

Lewis, S. T. 1998. Evaluation of habitat use by a transplanted bighorn sheep herd in Theodore Roosevelt National Park. Thesis, Montana State University, Bozeman, USA.

Lowrey, B., R. A. Garrott, D. E. McWhirter, P. J. White, N. J. DeCesare, and S. T. Stewart. 2018. Niche similarities among introduced and native mountain ungulates. Ecological Applications 28:1131-1142.

Lowrey, B., R. A. Garrott, H. M. Miyasaki, G. Fralick, and S. R. Dewey. 2017. Seasonal resource selection by introduced mountain goats in the southwest Greater Yellowstone Area. Ecosphere 8:e01769.

Lowrey, B., K. M. Proffitt, D. E. McWhirter, P. J. White, A. B. Courtemanch, S. R. Dewey, H. M. Miyasaki, K. L. Monteith, J. S. Mao, J. L. Grigg, et al. 2019. Characterizing population and individual migration patterns among native and restored bighorn sheep (Ovis canadensis). Ecology and Evolution 9:8829-8839.

Lula, E. S., B. Lowrey, K. M. Proffitt, A. R. Litt, J. A. Cunningham, C. J. Butler, and R. A. Garrott. 2020. Is habitat constraining bighorn sheep restoration? A case study. Journal of Wildlife Management 84:588-600.

Manlove, K. R., E. F. Cassirer, P. C. Cross, R. K. Plowright, and P. J. Hudson. 2014. Costs and benefits of group living with disease: a case study of pneumonia in bighorn lambs (Ovis canadensis). Proceedings of the Royal Society B: Biological Sciences 281:1-8. 
Manly, B. F., L. McDonald, D. Thomas, T. L. McDonald, and W. P. Erickson. 2002. Resource selection by animals: statistical design and analysis for field studies. Second edition. Springer, Boston, Massachusetts, USA.

McCarthy, J. J. 1996. History of transplanting mountain goats and mountain sheep - Montana. Pages 176-181 in Proceedings of the 10th Biennial Symposium. Northern Wild Sheep and Goat Council, Silverthorne, USA.

Montana Fish Wildlife and Parks. 2010. Montana bighorn sheep conservation strategy. Montana Fish, Wildlife \& Parks, Helena, USA. <http://fwp.mt.gov/fishAndWildlife/manag ement/bighorn/plan.html>. Accessed 15 Jul 2018.

Moses, M. E., B. Bessken, R. S. Gamo, S. Cordts, and F. J. Singer. 1996. Unique aspects of the ecology of bighorn sheep occupying a clay hills-prairie environment in Badlands National Park. Proceedings of the Biennial Symposium of the Northern Wild Sheep and and Goat Council 10:126-135.

National Agricultural Statistics Service. 2020. Census of Agriculture <https://www.nass.usda.gov/AgCensus/>. Accessed 25 Apr 2020.

Northrup, J. M., M. B. Hooten, C. R. Anderson, and G. Wittemyer. 2013. Practical guidance on characterizing availability in resource selection functions under a use-availability design. Ecology 94:1456-1463.

Omernik, J. M., and G. E. Griffith. 2014. Ecoregions of the conterminous United States: evolution of a hierarchical spatial framework. Environmental Management 54:1249-1266. Pebesma, E. 2018. Simple features for R: standardized support for spatial vector data. The R Journal 10:439-446. 
Pettorelli, N., S. J. Ryan, T. Mueller, N. Bunnefeld, B. Jedrzejewska, M. Lima, and K. Kausrud. 2011. The normalized difference vegetation index (NDVI): unforeseen successes in animal ecology. Climate Research 46:15-27.

Picton, H. D., and T. N. Lonner. 2008. Montana's wildlife legacy: decimation to restoration. Media Works Publishing, Bozeman, Montana, USA.

Poole, K. G., R. Serrouya, I. E. Teske, and K. Podrasky. 2016. Rocky Mountain bighorn sheep (Ovis canadensis canadensis) winter habitat selection and seasonal movements in an area of active coal mining. Canadian Journal of Zoology 94:733-745.

PRISM Climate Group. 2016. Oregon State University. $<$ http://prism.oregonstate.edu> . Accessed 28 Aug 2019.

R Core Team. 2020. R: a language and environment for statistical computing. R Foundation for Statistical Computing, Vienna, Austria.

Rominger, E. M. 2018. The Gordian knot of mountain lion predation and bighorn sheep. Journal of Wildlife Management 82:19-31.

Ruimy, A., B. Saugier, and G. Dedieu. 1994. Methodology for the estimation of terrestrial net primary production from remotely sensed data. Journal of Geophysical Research 99:5263.

Sappington, J. M., K. M. Longshore, and D. B. Thompson. 2007. Quantifying landscape ruggedness for animal habitat analysis: a case study using bighorn sheep in the Mojave Desert. Journal of Wildlife Management 71:1419-1426.

Sells, S. N., M. S. Mitchell, J. J. Nowak, P. M. Lukacs, N. J. Anderson, J. M. Ramsey, J. A. Gude, and P. R. Krausman. 2015. Modeling risk of pneumonia epizootics in bighorn sheep. Journal of Wildlife Management 79:195-210.

DeVoe et al. 29 
Shackleton, D. M., R. K. Steinhorst, and B. M. Wikeem. 1999. Natural history and Rocky

Mountain and California bighorn sheep. Pages 78-138 in R. Valdez and P. R. Krausman, editors. Mountain sheep of North America. University of Arizona Press, Tucson, USA.

Singer, F. J., V. C. Bleich, and M. A. Gudorf. 2000a. Restoration of bighorn sheep metapopulations in and near western National Parks. Restoration Ecology 8:14-24.

Singer, F. J., and M. Gudorf. 1999. Restoration of bighorn sheep metapopulations in and near 15 National Parks: conservation of a severely fragmented species. Volume 2: Synopsis of research findings. U.S. Geological Survey Open File Report 99-105, Fort Collins, USA.

Singer, F. J., M. E. Moses, S. Bellew, and W. Sloan. 2000b. Correlates to colonizations of new patches by translocated populations of bighorn sheep. Restoration Ecology 8:66-74.

Singer, F. J., C. M. Papouchis, and K. K. Symonds. 2000c. Translocations as a tool for restoring populations of bighorn sheep. Restoration Ecology 8:6-13.

Singer, F. J., and K. A. Schoenecker. 2004. Bighorn sheep habitat studies, population dynamics, and population modeling in Bighorn Canyon National Recreation Area, Wyoming and Montana, 2000-2003. U.S. Geological Survey, Biological Resource Discipline, Open-File Report 2004-1337, Reston, USA.

Singer, F. J., L. C. Zeigenfuss, and L. Spicer. 2001. Role of patch size, disease, and movement in rapid extinction of bighorn sheep. Conservation Biology 15:1347-1354.

Smith, T. S., J. T. Flinders, and D. S. Winn. 1991. A habitat evaluation procedure for Rocky Mountain bighorn sheep in the Intermountain West. Great Basin Naturalist 51:205-225.

South Dakota Department of Game Fish and Parks. 2018. South Dakota bighorn sheep management plan, 2018-2022. South Dakota Department of Game, Fish and Parks, Pierre, USA. <https://gfp.sd.gov/UserDocs/nav/bighornsheep_draft.pdf>. Accessed 28 Aug 2019.

DeVoe et al. 30 
Sweanor, P. Y., M. Gudorf, and F. J. Singer. 1996. Application of a GIS-based bighorn sheep habitat model in Rocky Mountain region National Parks. Biennial Symposium of the Northern Wild Sheep and Goat Council 10:118-125.

Tomkiewicz, S. M., M. R. Fuller, J. G. Kie, and K. K. Bates. 2010. Global positioning system and associated technologies in animal behaviour and ecological research. Philosophical Transactions of the Royal Society B: Biological Sciences 365:2163-2176.

Toweill, D. D. E., and D. V. Geist. 1999. Return of royalty: wild sheep of North America. Boone and Crockett Club and Foundation for North American Wild Sheep, Missoula, Montana, USA.

U.S. Forest Service. 2015. Bighorn sheep risk of contact tool v2 user guide. U.S. Forest Service/U.S. Bureau of Land Management Bighorn Sheep Working Group. $<$ https://www.fs.usda.gov/Internet/FSE_DOCUMENTS/fseprd527641.pdf $>$. Accessed 15 Aug 2019.

Valdez, R., and P. R. Krausman. 1999. Mountain sheep of North America. University of Arizona Press, Tucson, USA.

Wehausen, J. and R. Ramey. 2000. Cranial morphometric and evolutionary relationships in the northern range of Ovis canadensis. Journal of Mammalogy 81:145-161.

White, G. C., and R. A. Garrott. 1990. Analysis of wildlife radio-tracking data. Academic Press, New York, New York, USA.

Wickham, H., M. Averick, J. Bryan, W. Chang, L. D’Agostino McGowan, R. Francois, G. Grolemund, A. Hayes, L. Henry, J. Hester, et al. 2019. Welcome to the tidyverse. Journal of Open Source Software 4:1686.

DeVoe et al. 31 
Wiedmann, B. P., and B. Hosek. 2013. North Dakota bighorn sheep management plan (20132023). North Dakota Game \& Fish Department. <https:/gf.nd.gov/publications/597>. Accessed 28 Aug 2019.

Wild Sheep Working Group. 2012. Recommendations for domestic sheep and goat management in wild sheep habitat. Western Association of Fish and Wildlife Agencies. $<$ https://www.fs.usda.gov/Internet/FSE_DOCUMENTS/stelprdb5385708.pdf $>$. Accessed 15 Aug 2019.

Wockner, G., F. J. Singer, and K. Schoenecker. 2003. Habitat suitability model for bighorn sheep and wild horses in Bighorn Canyon and the Pryor Mountain Wild Horse Range. Colorado State University. <https://www2.nrel.colostate.edu/projects/bighorn/bighorn.pdf $>$. Accessed 15 Jul 2019.

Zeigenfuss, L. C., F. J. Singer, and M. A. Gudorf. 2000. Test of a modified habitat suitability model for bighorn sheep. Restoration Ecology 8:38-46.

Zimmerman, T. J. 2008. Evaluation of an augmentation of Rocky Mountain bighorn sheep at Badlands National Park, South Dakota. Thesis, South Dakota State University, Vermillion, USA.

Zimmerman, T. J., J. A. Jenks, R. W. Klaver, D. M. Leslie, and E. L. Childers. 2006. Use of digital elevation data to predict bighorn sheep habitat at Badlands National Park. Biennial Symposium of the Northern Wild Sheep and Goat Council 15:34-39.

Associate Editor: Kathryn Schoenecker.

DeVoe et al. 32 
700 Figure 1. Global positioning system (GPS) locations of 43 bighorn sheep instrumented in the

701 Fergus (A) and Middle Missouri Breaks (B) study areas in eastern Montana, USA, 2014-2018.

702 Inset map shows the extrapolation area across the prairie region of eastern (E.) Montana and

703 encompassing the estimated historical range of bighorn sheep (Couey 1950) and study areas. The

704 study areas represent annual ranges that were defined based on a 95\% kernel density estimate of

705 all locations for each population. Elevation is represented by the dark grey (low) to light grey

706 (high) gradient. Note differences in panel scales.

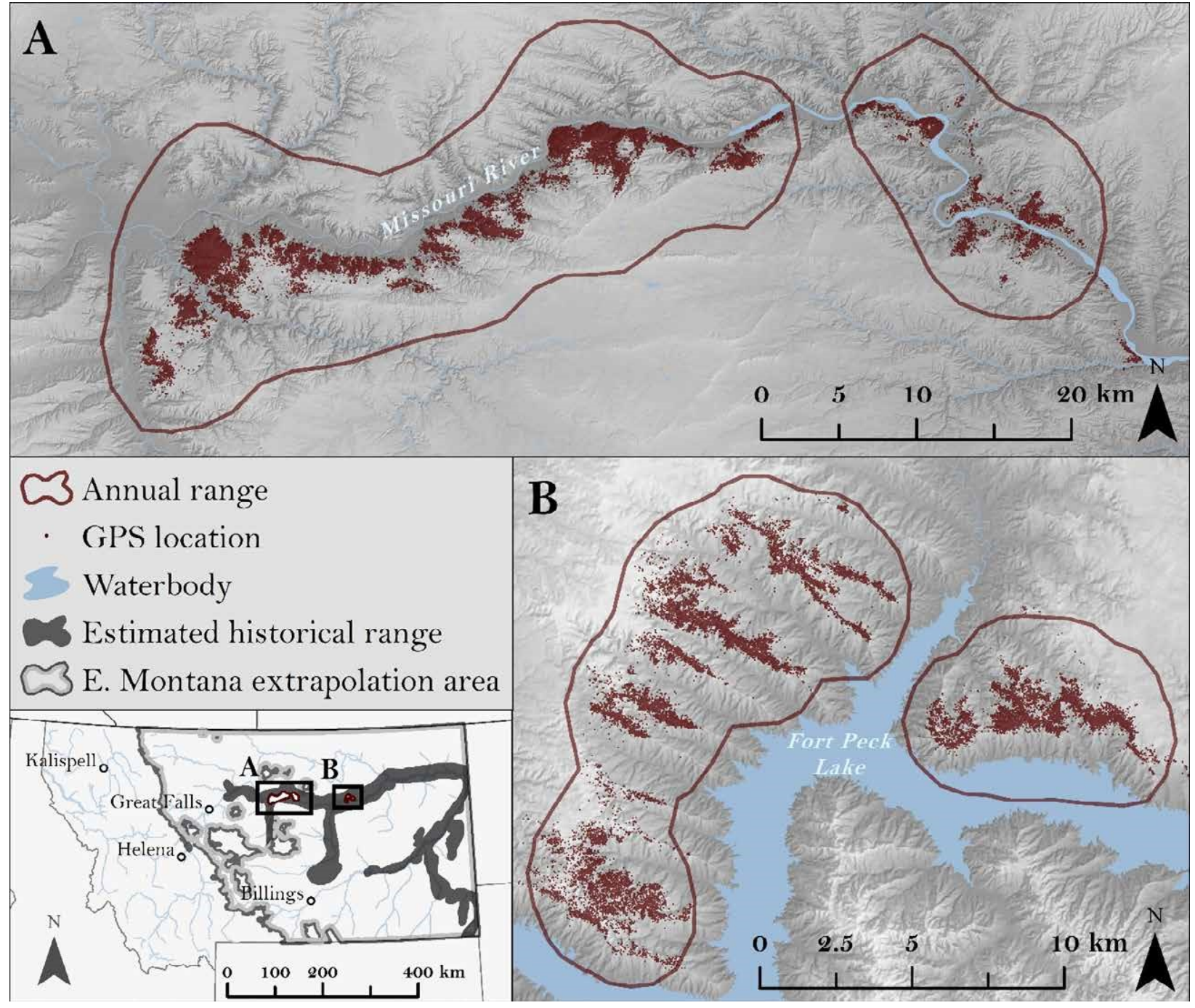


709 Figure 2. Predictive relationships of the relative probability of use (black line) and 95\%

710 confidence interval (shaded gray) across the range of observed covariate values estimated by

711 holding all other covariates constant at their mean value and using the final model of bighorn

712 sheep resource selection in the prairie region of eastern Montana, USA, 2014-2018. The

713 distribution of available and used locations across covariate values are represented by the lower 714 and upper rug, respectively. VRM = vector ruggedness measure, $\mathrm{NDVI}=$ normalized difference $715 \quad$ vegetation index.

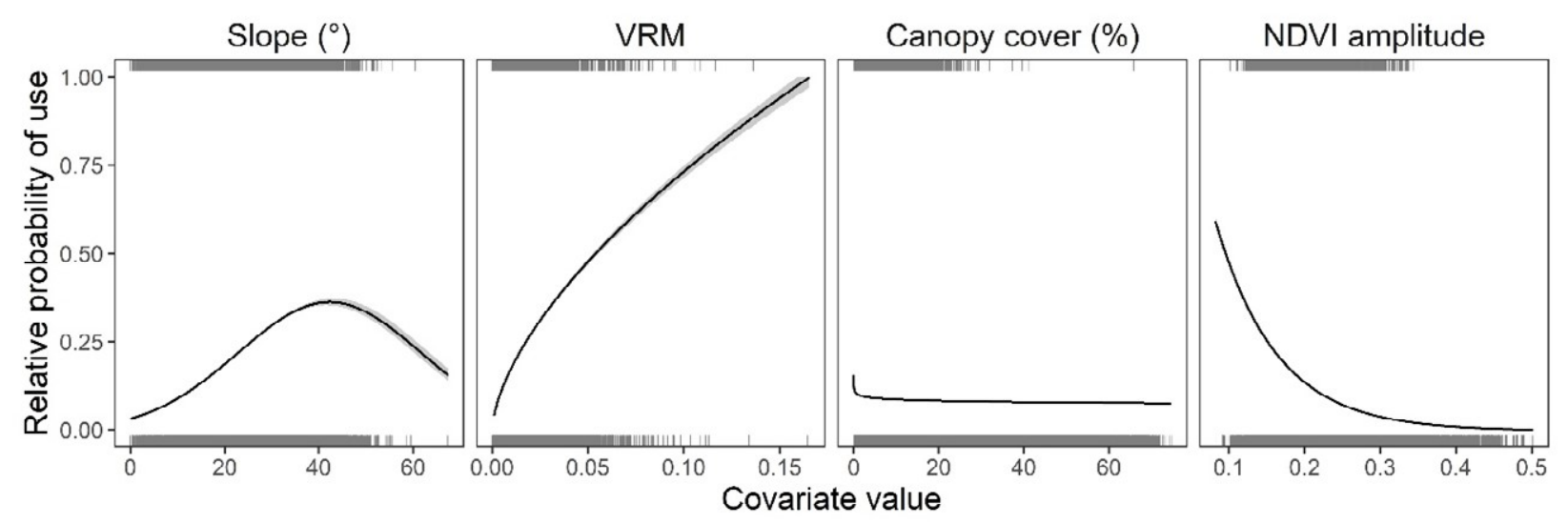

723 Figure 3. Extrapolation of the resource selection function (RSF) model for bighorn sheep 724

classified into habitat and overlaid on elevation (low $=$ dark grey, high $=$ white $)$ and the current 725 distribution of bighorn sheep in the prairie region of eastern (E.) Montana, USA, 2014-2018. 


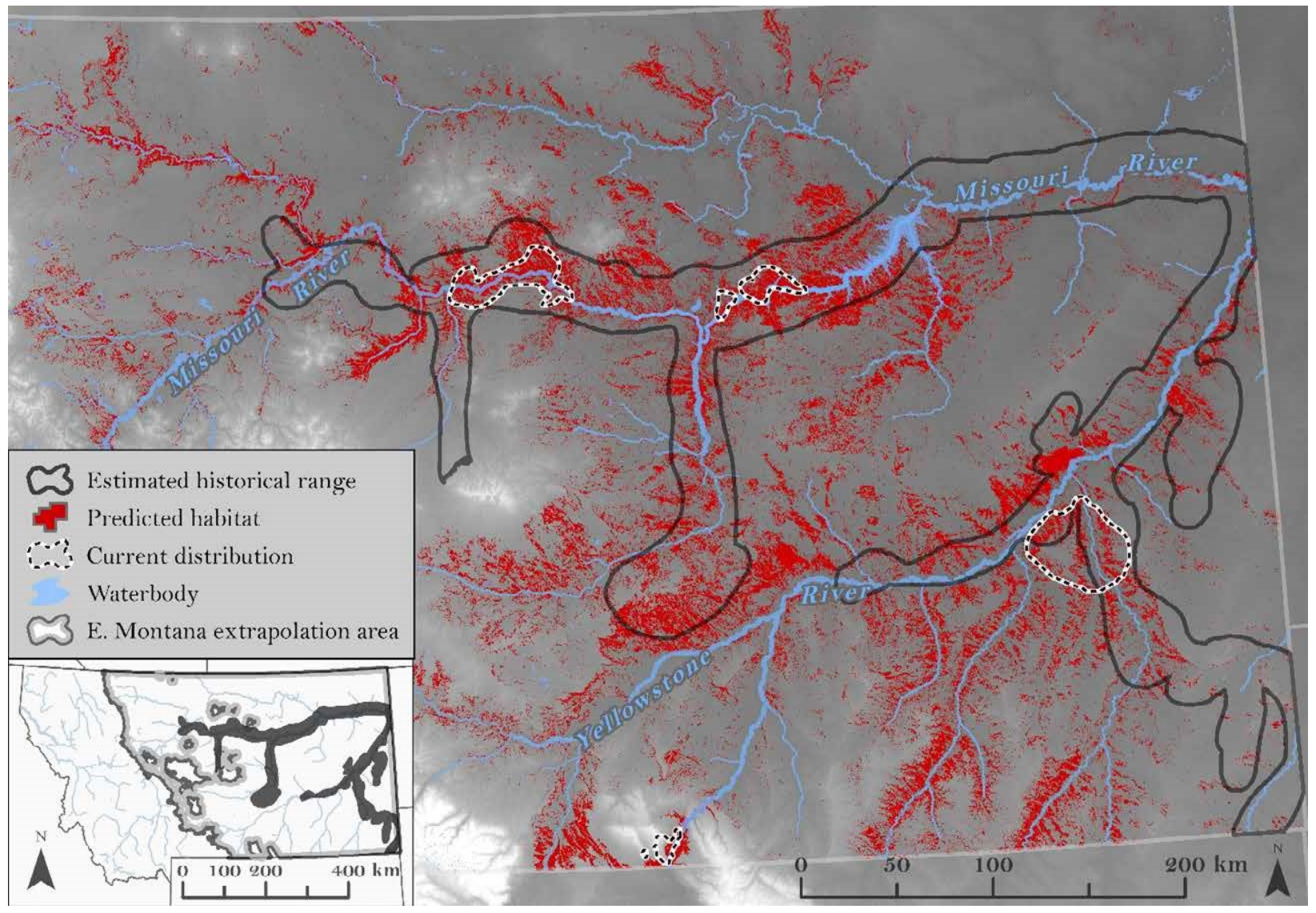

733 Figure 4. General land ownership, Montana hunting districts (http://gis-

734 mtfwp.opendata.arcgis.com, accessed $15 \mathrm{Jul}$ 2019), and estimated historical range of bighorn 735 sheep overlaid on elevation (low $=$ dark grey, high $=$ white $)$ in the prairie region of eastern 736 Montana, USA. 


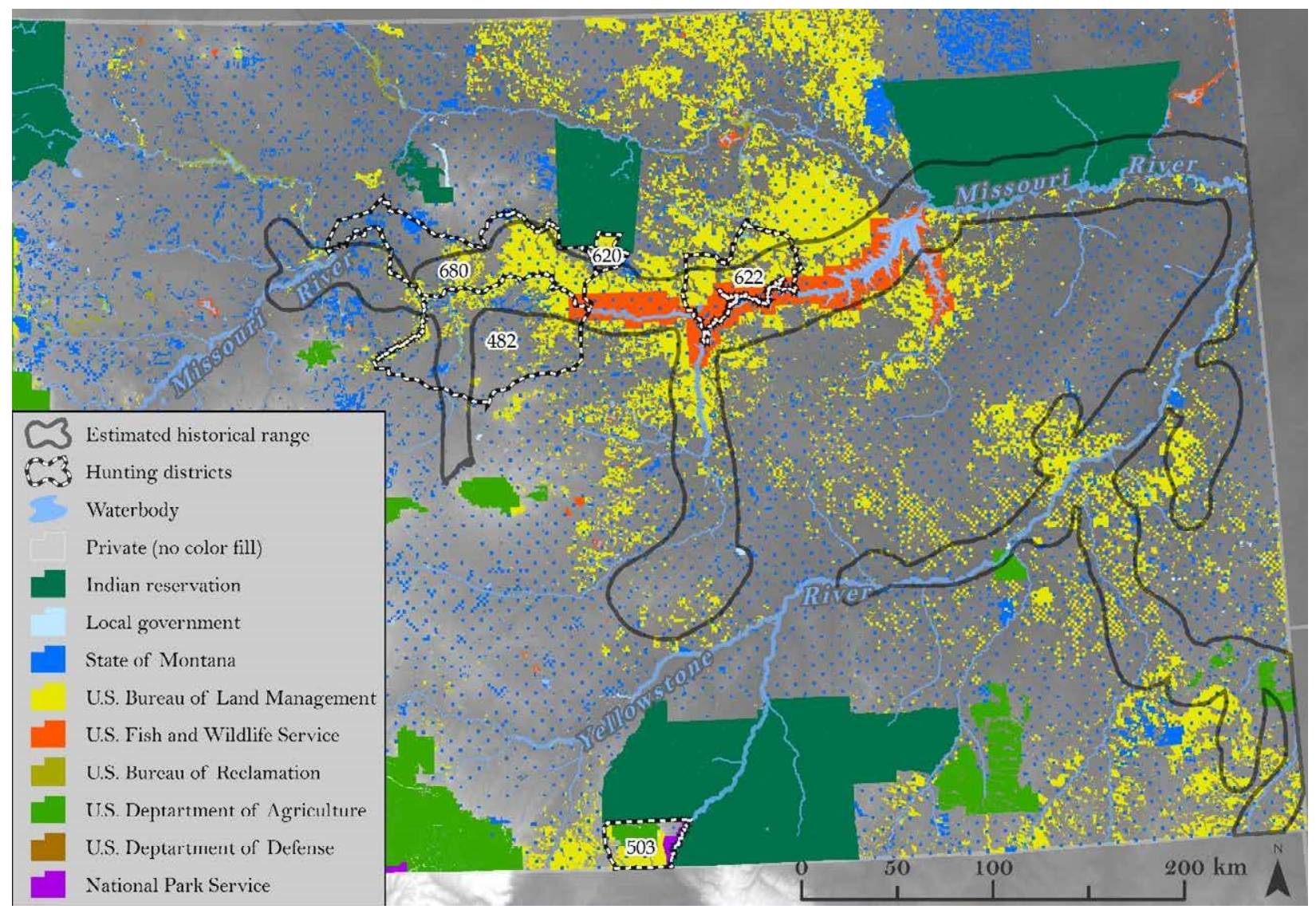

DeVoe et al. 36 
738 Table 1. Covariate descriptions and hypothesized direction of selection for covariates used in

739 modeling bighorn sheep resource selection in the Fergus and Middle Missouri Breaks study areas

740 in the prairie region of eastern Montana, USA, 2014-2018. Pseudothreshold forms are a natural log

741 transform.

742 Covariate

Description

Form $^{\mathrm{a}} \quad$ Reference

743

(hypothesis)

744

745 Terrain suite

746

747

748

749

750

751

752

753

754 Vegetation suite

755

Canopy cover

756

757

758
Degrees slope

$\operatorname{Li}(+), S q(+/-)$ Moses et al. (1996), Hickey

(2000), DeCesare and

Pletscher (2006)

Standard deviation ${ }^{2}$ of

slope

Vector ruggedness

measure
Li, Ps (+)

DeVoe et al. (2015),

Lowrey et al. (2018)

Li, Ps (+)

Sappington et al. (2007)
Tree canopy cover $(\%) \quad$ Li, Ps (-)

Mean difference between $\quad \mathrm{Li}(+)$

max. and baseline et al (2020) normalized difference 
vegetation index (NDVI)

at start of growing season

(May-Oct 2014-2017)

NDVI time-integrated Mean daily (interpolated) integration of NDVI

above the baseline for the

duration of the growing

season (May-Oct 2014-

2017)
Lowrey et al. (2018), Lula et al (2020) 
745 Table 2. Resource selection model selection results for tiers 1-3 comparing used and available

746 locations for bighorn sheep in the prairie region of eastern Montana, USA, 2014-2018. Models 747 are arranged by corrected Akaike's Information Criterion $\left(\mathrm{AIC}_{c}\right)$ ranking. For each model, we $748 \quad$ also present the number of parameters $(K)$ and $\mathrm{AIC}_{c}$ weight $\left(w_{i}\right)$.

\begin{tabular}{|c|c|c|c|c|c|}
\hline Model tier & Model $^{\mathrm{a}}$ & $K$ & $\mathrm{AIC}_{c}$ & $\Delta \mathrm{AIC}_{c}$ & $w_{i}$ \\
\hline \multirow[t]{8}{*}{ Tier 1} & Slope $^{2}$ & 4 & 726,767 & 0 & 1.0 \\
\hline & Slope & 3 & 732,104 & 5,338 & 0.0 \\
\hline & Slope variance $\mathrm{P}^{\mathrm{Ps}}$ & 3 & 740,757 & 0 & 1.0 \\
\hline & Slope variance & 3 & 773,860 & 33,102 & 0.0 \\
\hline & VRMPs & 3 & 737,883 & 0 & 1.0 \\
\hline & VRM & 3 & 768,036 & 30,153 & 0.0 \\
\hline & Canopy cover ${ }^{\mathrm{Ps}}$ & 3 & 784,380 & 0 & 1.0 \\
\hline & Canopy cover & 3 & 813,823 & 29,444 & 0.0 \\
\hline \multirow[t]{2}{*}{ Tier 2} & NDVI amplitude & 3 & 742,764 & 0 & 1.0 \\
\hline & NDVI time-integrated & 3 & 762,019 & 19,255 & 0.0 \\
\hline \multirow[t]{4}{*}{ Tier 3} & Slope $^{2}+$ VRM $^{\text {Ps }}+$ Canopy cover ${ }^{P s}+$ NDVI amplitude & 7 & 676,552 & 0 & 1.0 \\
\hline & Slope $^{2}+$ VRM $^{\text {Ps }}+$ NDVI amplitude & 6 & 681,956 & 5,403 & 0.0 \\
\hline & Slope $^{2}+$ VRM $^{\text {Ps }}+$ Canopy cover ${ }^{P s}$ & 6 & 692,498 & 15,946 & 0.0 \\
\hline & Slope $^{2}+V_{R M} M^{P s}$ & 5 & 703,728 & 27,176 & 0.0 \\
\hline
\end{tabular}

750 linear); VRM = vector ruggedness measure, NDVI = normalized difference vegetation index. 
752 Table 3. Summary of predicted bighorn sheep habitat in currently unoccupied areas within the 753 estimated historical range for each land ownership in the prairie region of eastern Montana, 754 USA. The area of the currently unoccupied historical range was $38,045 \mathrm{~km}^{2}$ and the area of

755 habitat in the currently unoccupied historical range was $7,211 \mathrm{~km}^{2}$.

\begin{tabular}{|c|c|c|c|c|}
\hline \multirow[t]{2}{*}{ Land ownership } & \multicolumn{2}{|c|}{ Within historical range } & \multicolumn{2}{|c|}{$\begin{array}{l}\text { Within predicted habitat } \\
\text { of the historical range }\end{array}$} \\
\hline & Proportion & Area $\left(\mathrm{km}^{2}\right)$ & Proportion & Area $\left(\mathrm{km}^{2}\right)$ \\
\hline Private & 0.621 & $23,634.55$ & 0.441 & $3,185.93$ \\
\hline Bureau of Land Management & 0.174 & $6,635.86$ & 0.330 & $2,385.05$ \\
\hline U.S. Fish and Wildlife Service & 0.064 & $2,450.70$ & 0.151 & $1,088.06$ \\
\hline State of Montana & 0.059 & $2,251.55$ & 0.068 & 493.68 \\
\hline U.S. Forest Service & 0.008 & 318.21 & 0.004 & 25.64 \\
\hline Fort Peck Indian Reservation & 0.069 & 2631.88 & 0.003 & 21.41 \\
\hline Water & 0.001 & 33.26 & 0.001 & 8.73 \\
\hline U.S. Department of Agriculture & 0.002 & 56.35 & 0.001 & 5.13 \\
\hline City government & 0.001 & 19.95 & 0.001 & 3.97 \\
\hline County government & 0.001 & 29.10 & $<0.001$ & 1.46 \\
\hline U.S. Department of Defense & $<0.001$ & 6.17 & $<0.001$ & 1.21 \\
\hline Bureau of Reclamation & $<0.001$ & 4.54 & $<0.001$ & 0.57 \\
\hline Fort Belknap Indian Reservation & $<0.001$ & 0.01 & $<0.001$ & 0.01 \\
\hline
\end{tabular}


759 We characterized and defined bighorn sheep habitat in the eastern Montana, USA, region of the

760 Northern Great Plains and predicted habitat throughout currently unoccupied areas within and

761 outside the historical bighorn sheep range. Our results highlight potential for bighorn sheep

762 restoration within a prairie region and provide a predictive habitat model that could be used to

763 identify potential translocation sites in similar environments in the Northern Great Plains. 